\title{
O ensaio entre a arte e a ciência: entrevista com Henri Arraes Gervaiseau
}

\section{Por Jamer Guterres de Mello}

Doutorando; Universidade Federal do Rio Grande do Sul jamermello@gmail.com

\section{Gabriela Machado Ramos de Almeida}

Doutora; Universidade Federal do Rio Grande do Sul gabriela.mralmeida@gmail.com

Henri Arraes Gervaiseau é cineasta e professor da ECA-USP. Tem artigos publicados em revistas brasileiras e estrangeiras. É autor de $O$ abrigo do tempo: abordagens cinematográficas da passagem do tempo (2012). Entre os seus documentários, premiados no Brasil e no exterior, destacam-se: Tem que ser baiano? (1994); Terra Prometida (1997); Em trânsito (2005); Retrato de grupo (2009); Entretempos (2012). O seu projeto de pesquisa atual tem como tema central o documentário, mas particularmente de cunho ensaístico, como meio de expressão da experiência do deslocamento. Nesta perspectiva, reflexão teórica, revisão crítica e análise de uma série de obras estrategicamente escolhidas encontram-se associadas à elaboração de ensaios audiovisuais inéditos que envolvem a própria experiência existencial de deslocamento do pesquisador realizador, francobrasileiro. Henri Arraes Gervaiseau dedica-se atualmente a preparação do primeiro filme da sua Trilogia do deslocamento.

Esta entrevista foi realizada por ocasião da sua visita a Porto Alegre, em março de 2015, para realização da aula inaugural do Programa de Pós-Graduação em Comunicação e Informação da Universidade Federal do Rio Grande do Sul (PPGCOM/UFRGS). Na conversa, Gervaiseau reflete sobre o espaço do ensaio como lugar de produção de conhecimento, as fronteiras entre o ensaio, a arte e o texto científico e a prática ensaística no audiovisual. 
É possível perceber no Brasil uma resistência muito grande, principalmente no campo acadêmico, em relação ao ensaio como uma escrita possível para a produção de conhecimento científico. Qual a sua percepção? O ensaio cabe ao campo científico?

Quanto à resistência acadêmica à dimensão do ensaio, não tive oportunidade de conhecer propostas de escrita ensaística que tenham sido recusadas. No que concerne pesquisadores em processo de formação, no contexto universitário, espera-se que os textos das suas dissertações e teses sejam de cunho argumentativo, que sigam métodos de cunho hipotético-dedutivo, e não sejam ordenados por uma lógica de cunho associativo ou poético.

0 ensaio configura um tipo de discurso particularmente exigente quanto ao seu modo de composição, e pressupõe, por parte de quem o elabora, independente de sua idade, um bom nível de maturidade intelectual e pessoal. 0 que é possível, mas ainda extremamente raro de encontrar, são dissertações ou teses em que a parte escrita do trabalho está intrinsicamente associada a um ensaio audiovisual. É difícil conseguir construir, de modo orgânico, esta articulação. As pessoas ainda não estão muito preparadas para lidar com este tipo de proposta, e levá-la a cabo. Por isso é frequente uma oposição maior dentro da instituição acadêmica. No caso de pesquisadores que já possuem uma carreira acadêmica mais consolidada, apesar da produção escrita ensaística não ser comum, não considero que haja uma resistência essencial.

Cabe observar, entretanto, como já tem sido sublinhado por muitos colegas, que vivemos, nas circunstâncias históricas atuais, em função de exigências das agências de financiamento, um período, dentro da instituição acadêmica, em que impera um certo tipo de produtividade textual e um padrão de texto mais objetivo, curto, sem a densidade exigida por textos de cunho ensaístico, na acepção clássica do termo.

Para além do campo de estudos do cinema, no campo das ciências humanas, de modo mais amplo, há resistência à explicitação, no corpo do próprio discurso, da posição e do ponto de vista do sujeito enunciador. Se tomarmos como exemplo uma disciplina específica das ciências humanas, que é a História, só recentemente, dentro do campo historiográfico, é que surgem estudos que dialogam de modo mais abrangente com uma abordagem de cunho ensaístico. É verdade que, desde 1987, o sempre instigante historiador francês Pierre Nora tinha cunhado o termo de ego história, que pretendia fundar como um novo gênero historiográfico, que dialoga de modo mais efetivo com o campo autobiográfico.

A obra historiográfica mais notável, nos últimos anos, que transcende o campo autobiográfico, embora com ele se relacione, é para mim História dos avós que eu não tive, 
um inquérito, de Ivan Jablonka (2012), historiador francês de quarenta e poucos anos, neto de judeus comunistas poloneses que se refugiaram na França, no inicio da Segunda Guerra. Com a ocupação alemã, e a colaboração do estado francês com o regime nazista, seus avós foram deportados pra Auschwitz, onde faleceram. Antes da deportação, porém, conseguiram confiar seus dois filhos, Suzanne e Marcel (este último pai do historiador) a um casal de franceses, que os acolheu e criou. Há mais ou menos dez anos, Ivan Jablonka quis saber dessa história, à qual seu pai, ao longo de sua vida, pouco tinha se referido, em função da força do trauma vivido. Este historiador então empreende uma pesquisa em muitos arquivos na Polônia e na França, entrevista muitas pessoas, inclusive na Argentina e em Israel. Realiza, enfim, uma longa pesquisa com vistas a reconstituir a história de seus avós, levando em consideração o contexto mais amplo em que esta história se insere, ao mesmo tempo em que explicita o ponto de vista em que se situa como enunciador. Ele constrói uma narrativa da sua própria investigação, e expõe o desenvolvimento progressivo do seu raciocínio, o movimento do seu pensamento. Eu poderia, me apropriando de conhecida frase de Adorno, dizer que o referido ensaio historiográfico de Jablonka "torna-se verdadeiro pela marcha do seu pensamento, que o leva para além de si mesmo [...]". (ADORNO, 2003). 0 livro de Jablonka (2012) é uma obra extraordinária. O autor, ainda relativamente jovem, já publicou vários livros de história. É professor de História na Universidade de Paris 13, e redator chefe da revista on line La vie des idées.

Se por um lado o ensaio exige uma certa maturidade intelectual, pois é um tipo de escrita que talvez não caiba em um processo de formação, por outro lado, em relação aos pesquisadores que já possuem uma trajetória de investigação e de pesquisa, é possível questionar se o texto científico mais clássico e objetivo consegue dar conta das questões do nosso tempo plenamente. É possível dizer que há uma demanda por uma posição um pouco mais subjetiva do pesquisador em relação ao modo como ele olha seus objetos?

Eu não formularia a questão exatamente deste modo. Não me parece que a questão central seja a necessidade de uma posição um pouco mais subjetiva do pesquisador em relação ao modo como ele olha seus objetos. Trata-se de tornar mais explícito o ponto de vista a partir do qual o pesquisador se situa.

As tradições mais instigantes e consistentes, no campo do ensaio, não são forçosamente aquelas em que há uma exacerbada exposição da subjetividade do 
enunciador, mas uma problematização da relação do enunciador com aquilo que ele enuncia, uma problematização da sua posição.

$\mathrm{Na}$ obra de um dos cine-ensaístas mais instigantes da segunda metade do século XX, Harun Farocki, não transparece uma subjetividade, mas a abordagem, a partir de um ponto de vista claramente situado, de determinada questão que lhe interessa discutir, quer esta questão seja de ordem histórica, estética ou política. Não é por acaso que Didi-Huberman (2010), ao discutir a sua obra, qualifica Farocki de "cineasta na terceira pessoa". Em torno da questão escolhida, este recém-falecido cineasta alemão vai procedendo a uma série de associações e desenvolvendo interrogações sucessivas que se articulam em torno da questão principal. Assistimos ao desenvolvimento de um raciocínio aparentemente um pouco errático, mas que, de fato, é sempre fruto de um trabalho de composição bastante rigoroso.

A dimensão subjetiva do ensaio é uma questão que na bibliografia existente é frequentemente sobrevalorizada, se excetuarmos autores como Antônio Weinrichter ou Timothy Corrigan (2011), por exemplo. Este último autor, nas suas considerações a respeito das principais características do filme-ensaio, sintetiza bem a questão: a atividade ensaística é uma atividade que produz uma interseção entre três pontos: a expressão pessoal, $a$ experiência pública e o processo de pensamento. 0 encontro entre um eu aberto e a experiência social produz a atividade do pensamento, que por sua vez leva a um reposicionamento do eu. Este processo envolve a produção de uma narrativa da experiência vivida do mundo por uma mente que pensa. Como Corrigan (2011) sublinha, o mais interessante no ensaístico não é tanto como privilegia a expressão pessoal, mas, antes, a maneira como problematiza a própria noção de expressividade e a sua relação com a experiência.

Nos filmes ensaios mais instigantes, a ênfase colocada sobre a distância existente entre a realidade da experiência vivida e sua representação, longe de ter por objetivo negar toda verdade à representação que o filme constrói, visa estimular a capacidade de reflexão do espectador, para que ele possa, tomando consciência das lacunas da representação, melhor apreender a complexa textura do conjunto de ocorrências que compõe a dimensão propriamente humana e/ou histórica das experiências vividas.

Em certos tipos de ensaios, a subjetividade - no sentido emocional, afetivo ou biográfico - do sujeito enunciador, pode se revestir de uma importância maior, como no caso 
de Santiago, de João Moreira Salles. Há, é claro, uma gama muito diversificada de abordagens ensaísticas possíveis.

Devo ressaltar que na bibliografia brasileira, nem sempre a existência desta diversidade é destacada com suficiente clareza. Há, com frequência, uma ênfase excessiva na dimensão subjetiva do ensaio. Esse equívoco pode ser encontrado na bibliografia internacional relativo ao ensaio, mas me parece que entre nós é, até o presente momento, mais recorrente.

E aí ocorre um problema, pois quase todo discurso autobiográfico acaba cabendo no ensaio, nessa determinada produção bibliográfica nacional.

Sim, e não é que não existam formas ensaísticas de autobiografia. A obra de Jonas Mekas, por exemplo, que tem uma dimensão autobiográfica muito clara, também é de cunho essencialmente ensaístico. Outro exemplo é a obra de Ross McElwee, que é norte-americano.

Ao que tudo indica, na história do cinema documentário norte americano, há uma forte tradição autobiográfica, muito mais do que no cinema documentário brasileiro, que só mais recentemente tem se aberto para essa vertente do espaço biográfico. Mas nem todo filme autobiográfico é de cunho ensaístico, e nem todo filme ensaístico é autobiográfico. Como já foi dito a propósito da obra de Montaigne, o ensaio não registra, prioritariamente, as ações daquele que escreve, mas suas cogitações.

Montaigne propõe, de certa forma, uma escrita que coloca em jogo a tomada de consciência sobre o próprio ato de escrita. Se podemos pensar o ensaio como uma reflexão sobre uma prática de um determinado sujeito, que seria o próprio ensaísta, e como já foi dito, dentro de um amplo leque em que o ensaio pode ser mais ou menos subjetivo, existe uma questão que é muito cara ao ensaio, principalmente no campo do audiovisual, que é uma imprecisão conceitual ou de terminologia. Há uma dificuldade de sintetizar uma definição que seja operativa desse ensaio. Se o ensaio audiovisual não é passível de uma definição como modelo geral, como gênero, é possível determinar um conceito de ensaísmo, que talvez não seja encerrado em si mesmo, mas múltiplo e aberto?

A aula inaugural que eu dei na Faculdade de Biblioteconomia e Comunicação da UFRGS, a convite do PPGCOM, constitui um desdobramento do texto que redigi para compor um capitulo de um livro, organizado por Francisco Elinaldo Teixeira, a ser lançado em breve, que reúne contribuições de diversos autores a respeito do filme-ensaio. Nesta aula inaugural, fiz referência às diversas discussões existentes no campo da teoria literária sobre essa classe textual. 
De modo resumido, é sempre importante lembrar que na grande tradição do ensaio, a busca da verdade é incessantemente remetida a uma existência particular e a uma experiência vivida na duração. Como apontou Mathieu-Castellani, grande especialista em Montaigne, a problemática do ensaio é a de ser uma experiência que se vive e se decifra no trabalho da escrita que a diz. Outro traço característico do ensaio é o seu próprio andamento poético, de cunho paratático, associativo.

Há, evidentemente, especificidades relativas à dimensão audiovisual: a ampla variedade de matérias de expressão colocadas em jogo; a relação da passagem das imagens com a memória e a montagem; e os modos enigmáticos de articulação das matérias de expressão. Como ensaios audiovisuais, de modo geral, evocam realidades históricas, culturais ou sociais preexistentes, frequentemente são compostos a partir da incorporação de vestígios, de objetos já formados, analiticamente decompostos e sinteticamente recompostos no processo da montagem. Josep Català, em um estudo recente, observa de modo pertinente, que no caso do uso, em filmes ensaios, de imagens fotográficas, o cineasta não atua sobre uma matéria insignificante (a pedra, a tela ou o papel), mas incorpora, no seu trabalho de composição audiovisual, uma matéria já pensada, uma imagem técnica. Levando em consideração as especificidades desta nova matéria de expressão que é a imagem de base fotoquímica (e depois eletrônica e digital), o artista propõe pensamentos, através da montagem, da colagem, etc. (CATALÁ, 2014).

A prática do ensaísmo no audiovisual acaba transformando o filme em um objeto livre, que não se ajusta aos parâmetros e imperativos clássicos do cinema como instituição, que inventa sua própria fórmula e produz (como na literatura) um pensamento aberto a múltiplos territórios, como falávamos antes. Alguns autores, como Weinrichter, consideram o ensaio como uma evolução, uma espécie de maturidade da expressão cinematográfica. Como você pensa esta questão entre ensaio e cinema?

Instigante observação de Weinrichter. Para entendê-la, é importante, antes, lembrar, como eu o fiz no meu livro $O$ Abrigo do tempo, que a ideia da montagem de registros, de reunião de fragmentos da realidade registrada a fim de produzir novos objetos artísticos, cresce e se desenvolve simultaneamente ao início da montagem cinematográfica, no decorrer das primeiras décadas deste século, em meio a diferentes correntes da vanguarda literária e plástica europeia (GERVAISEAU, 2012).

No início do século XX, Apollinaire preconiza a utilização do fonógrafo como novo meio de expressão poética. Para renovar sua inspiração, o poeta deveria, segundo ele, 
reportar-se à natureza, à vida, observar a verdade exterior e registrar o lirismo ambiente, graças ao fonógrafo, aos sons e às frases ouvidas nos trens ou nas ruas, a fim de elaborar um novo tipo de poema que ele nomeia poema conversação. Os pintores cubistas, que exercem profunda influência sobre a vanguarda russa, rejeitaram, como sabemos, os conteúdos literários e anedóticos e se voltaram para temas e, sobretudo, objetos mais próximos do cotidiano, impregnados de humanidade, que eles introduziam, através da colagem, em seus quadros. A expressão impregnados de humanidade é de Apollinaire, amigo dos cubistas. Lembremo-nos das colagens em trompe-l'oeil de Braque (1910), dos papéis colados e do uso de fragmentos tipográficos feitos por Picasso (1911-1912), ou dos fragmentos de jornal ou de pacotes de tabaco. Como esses objetos integravam, com muita frequência, a experiência humana anterior do público, a ideia era que eles pudessem servir de elementos mediadores entre os modos habituais de percepção e os novos procedimentos artísticos, a fim de estabelecer novos modos de percepção. Ian Christie levantou a interessante hipótese de uma influência do cinema sobre a obra de Picasso. Ele destaca o interesse do pintor pelo cinema desde 1896 e particularmente no decorrer do período de gestação das primeiras telas cubistas de 1907. Segundo ele, há um parentesco entre o interesse do artista pelo cinema e suas incursões na colagem e na escultura (CHRISTIE, 1995). A colagem evoluiu em direção à reunião de objetos ou fragmentos de objetos, cuja aproximação levava à produção de significações originais, inéditas. Esse tipo de operação encontrava-se na base da fotomontagem, outra prática artística do início do século que aparece nas proximidades de Dada e retira do caos da guerra e da revolução uma nova visão do mundo, marcada por efeitos visuais inesperados e desestabilizadores, como já apontou Frizot (FRITZOT, 1987). 0 material de base, constituído com frequência por imagens da atualidade, é dividido em fragmentos e transformado por seu modo de composição, descentrando a figura humana de sua posição habitual no enquadramento, e constituindo um quadro inédito do ambiente usual do homem moderno. As fotomontagens de Rodchenko, baseadas no princípio da autorreferência, precedem a emergência do cinema anti-ilusionista de Vertov, com quem o fotógrafo virá colaborar.

Toda essa busca das artes plásticas, da poesia, e também do cinema, com Vertov, em particular, de alguma maneira se perdeu com o crescimento avassalador da influência da propaganda, no campo do cinema, nos anos 30, e a tragédia da Segunda Guerra Mundial. Como Timothy Corrigan (2011) apontou, retomando observações de Paul Arthur (2003), foi depois do holocausto, teste limite da nossa era para o papel do testemunho individual no 
trauma coletivo, que o filme-ensaio adquiriu um perfil estético distinto e um projeto moral. A crise da segunda guerra mundial, e, para além do holocausto, o trauma que se transportou de Hiroshima através do mundo, e ainda, a guerra fria, produziu e informou uma crise social, existencial, representacional que iria galvanizar o imperativo ensaístico de questionar e debater não apenas um novo mundo, mas também os próprios termos através dos quais subjetivamente habitamos e vivenciamos este mundo (CORRIGAN, 2011). Não é, sem dúvida, um acaso se um dos procedimentos de montagem mais recorrentes no estágio inicial de emergência do filme-ensaio, que é a do pós-guerra, foi o de tensionar a relação entre texto e imagem, e de modo mais especifico entre a voz enunciadora e a imagem, já que no cinema de propaganda do entre guerras e da Segunda Guerra Mundial, que instrumentalizou a potência de testemunho e de persuasão da imagem de base fotoquímica, vigorou a domesticação da imagem pelo conteúdo ideológico veiculado pelo texto. É dentro desta história trágica do cinema, estreitamente entrelaçada com a história do século XX, que pôde efetivamente surgir o filme-ensaio, num novo e instigante patamar de evolução dos modos cinematográficos de expressão.

Então eu concordo, acho que a questão ensaística na experiência cinematográfica tem ligação com uma maturidade, uma evolução do próprio cinema.

Godard dizia que o cinema teria uma vocação não realizada, pois para ele o cinema pode ter nascido para gerar conhecimento e não para contar histórias. Nora Alter afirma que o ensaio pode ser uma forma (ou uma não forma) reprimida por outros gêneros cinematográficos, o horizonte ao qual tende o cinema para recuperar e cumprir sua primordial vocação subjugada de gerar conhecimento. Como você vê a possibilidade de produção e expressão de um pensamento e de produção de conhecimento através do ensaio fílmico?

Na obra em que está mais amplamente desenvolvido o pensamento de Godard a respeito da história do cinema, a dimensão liricamente mais exaltada é a da força de testemunho do cinematográfico. 0 que explicitamente encontra-se enunciado, poeticamente, pelo narrador está ligado à capacidade de produção de uma memória a partir da capacidade do cinema de recolher vestígios, rastros do que foi. A partir da incorporação de uma dimensão, em outras palavras, factual - frequentemente desprezada em tempos pósmodernos. A ênfase colocada nessa dimensão não elimina o fato de que o discurso que o conjunto da série Histoire(s) du cinéma produz visa também a exaltar a capacidade do cinema de produzir pensamento. Não é por acaso que a série termina com um episódio que 
se chama Os signos entre nós. Através da montagem, da associação de registros, de imagens, sons, textos, etc., é possível que se produzam enunciados e que esses enunciados instigantes e desconcertantes possam vir a suscitar reflexões e, nesse sentido, estimular o conhecimento.

O que eu acho interessante, e essa é uma dimensão muito rica de uma certa linhagem do filme-ensaio, é que ela visa a produzir conhecimento a partir do momento em que aposta na existência de um espectador emancipado, que é algo que já se encontrava em Vertov. Há uma frase de Eisenstein, na sua polêmica com Vertov, em que qualifica $O$ homem com a câmera, de palhaçada formalista. Se no melancólico contexto de retrocesso da vanguarda soviética do final dos anos 20 e dos anos 30 Eisenstein pôde fazer tal afirmação, isto se deve ao fato de que neste filme nenhuma narrativa aparente une ou explica a articulação subterrânea dos temas, as vertiginosas associações de imagens que se sucedem no filme. Entretanto, se você é um espectador que se detém de forma mais paciente para ver como é que se entrelaçam progressivamente as imagens, sejam contíguas ou distantes, você vai percebendo como as associações vão se estabelecendo no curso do desenrolar do filme, e consegue perceber qual o seu sentido.

Filmes ensaios podem efetivamente vir a produzir conhecimento e constituir um modo instigante de produção de conhecimento. Um modo, talvez, mais exigente, mais também mais frutífero, que interpela o espectador, e exige uma participação mais ativa deste no processo de compreensão da obra.

Os melhores ensaios envolvem vários níveis de leitura. Entre outros: rítmico, emocional, e de cunho mais intelectual. Para que o espectador possa alcançar uma dimensão mais heurística de produção de conhecimento, a sua atenção tem de ser mantida por essas outras dimensões. Por isso, também, o discurso ensaístico audiovisual é mais exigente e demanda uma maior maturidade em termos de composição, porque ele é um discurso menos facilmente assimilável.

A própria série Histoire(s) du cinéma, se você se deixa levar pela inflação aparentemente desordenada e acachapante de informações visuais e sonoras, o impacto inicial que se tem é basicamente rítmico, emocional, sensorial ou plástico. Você pode, virtualmente, de modo progressivo, apreender o conteúdo semântico da série, dos seus capítulos e episódios, mas não é algo imediatamente muito evidente. Algo desta ordem acontece também com os filmes de Farocki, embora de maneira diferente. 
Agora, eu não afirmaria, de modo tão categórico, que a vocação original do cinema era a de produzir o conhecimento. A sua vocação inicial, além de ser um modo de registro e de testemunho, até então inédito, era mesmo a de divertir mesmo. A frase de Godard, no final das contas, é um discurso de combate interessante e, claro, a gente assina embaixo.

O ensaio não filma e organiza o mundo ao modo do documentário clássico, mas sim procura constituir o mundo. Pode-se afirmar que cada filme-ensaio é um caso particular. Não haveria, portanto, uma particularidade do ensaísmo, mas antes, particularidades de cada filme-ensaio. $O$ ensaio poderia funcionar como um antídoto contra a sujeição do documentário à ideia problemática da representação? De que forma se pode pensar essa íntima relação entre o ensaio e o documentário?

Dentro de uma sociedade, de um campo de estudos ou em um campo artístico ocorrem manifestações, obras vão sendo produzidas, e a partir de um certo momento, ganham destaque, entre outras razões possíveis, pela sua recepção junto ao público ou pela sua recepção crítica. Há uma apreciação dessas obras, há um tipo de discurso reproduzido sobre elas, há uma sistematização em defesa de certos tipos de procedimentos artísticos e técnicos utilizados, e isso acaba criando o que se convencionou chamar de tradições. Tradições vão, deste modo, surgindo, sendo inventadas, só que na dinâmica da história, em determinado momento, por razões diversas, uma tradição se sobrepõe as outras, na luta pela hegemonia, no campo sociocultural em que se situa.

O documentário é um campo que se definiu historicamente no território do cinema de forma tardia. É significativo que em diversos países, e particularmente nos EUA, tenha se usado preferencialmente, para diferenciar este campo, o termo de não ficção. Ora, para haver não ficção, pressupõe-se que tenha se previamente configurado um campo denominado de ficção, que não surgiu ex-nihilo com o advento do cinematógrafo. Foi preciso que a indústria cinematográfica americana progressivamente configurasse este domínio da ficção, apartado do mundo histórico, mas que se revestisse de todas as aparências visíveis da realidade, para que as pessoas pudessem nela projetar-se.

0 que foi se configurando como a tradição do documentário é apenas uma das tradições que se configuraram na história do cinema. Por uma série de fatores, esta tradição se tornou, durante muito tempo, hegemônica. Refiro-me aqui à tradição que a escola inglesa dos anos trinta configurou, a do documentário expositivo, na qual, efetivamente, não há uma problematização da representação. 0 que ocorre, contrariamente, em filmes documentários do entreguerras tão diversos quanto $O$ Homem com a câmera (1929) de Dziga Vertov, Chuva 
(1929) de Joris Ivens, À propos de Nice (1930) de Jean Vigo, e Terra sem pão (1933) de Luis Buñuel.

A discussão que Corrigan (2011) propõe me parece bastante pertinente: o filmeensaio na sua versão moderna surge no pós-guerra, num momento em que se coloca claramente a questão da representação do mundo histórico, já que não era possível representar o mundo da mesma forma, após Auschwitz.

0 que procuramos designar hoje em dia como ensaio e a tentativa de estabelecimento de um domínio que seria próprio do ensaio está muito ligado à necessidade de repensar a relação entre o mundo histórico e a sua representação. Essa interrogação sobre a linguagem, de forma mais radical, é algo que singulariza o ensaio em relação ao documentário mais convencional.

\section{Referências}

ADORNO, T. 0 ensaio como forma. In: Notas de Literatura. São Paulo: Duas Cidades/Ed 34, 2003. p. 15-45.

ARTHUR, P. Essay questions. Film Comment, New York, v. 39, n. 1, p. 58-62, 2003.

CATALÀ, J.. M. Estética del ensayo: la forma ensayo, de Montaigne a Godard. Valencia: PUV/Universitat de Valência, 2014.

CHRISTIE, I. L'avant-garde internationale et le cinéma. In: TOULET, E. (Org.). Le cinéma au rendez-vous des arts: France, années 20 et 30. Paris: Bibliothèque Nationale de France, 1995. p. 68-76.

CORRIGAN, T. The essay film, from Montaigne, after Marker. Oxford University Press. 2011.

DIDI-HUBERMAN, G. Remontages du temps subi: l'oeil de l'histoire, 2. Paris: Éditions de Minuit, 2010.

FRIZOT, M. Les vérités du photomenteur. In: Photomontages: photographie expérimentale de l'entre-deux-guerres. Paris: Photo Poche, 1987. p. 1-9.

GERVAISEAU, H. A. 0 abrigo do tempo: abordagens cinematográficas da passagem do tempo. São Paulo: Alameda, 2012.

JABLONKA, I. Histoire des grands parents que je n'ai pas eu: une enquête. Paris: Seuil, 2012. 